\title{
Ionic Liquid-Assisted Liquid-Liquid Microextraction based on the Solidification of Floating Organic Droplet in Sample Preparation for Simultaneous Determination of Herbicide Residues in Fruits
}

\author{
Jitlada Vichapong, ${ }^{1, *}$ Yanawath Santaladchaiyakit, ${ }^{2}$ Rodjana Burakham ${ }^{3}$ \\ and Supalax Srijaranai ${ }^{3}$ \\ ${ }^{1}$ Creative Chemistry and Innovation Research Unit, Department of Chemistry and Center of Excellence for Innovation in \\ Chemistry, Faculty of Science, Mahasarakham University, Mahasarakham 44150, Thailand \\ ${ }^{2}$ Department of Chemistry, Faculty of Engineering, Rajamangala University of Technology Isan, Khon Kaen Campus, \\ Khon Kaen 40000, Thailand \\ ${ }^{3}$ Materials Chemistry Research Center, Department of Chemistry and Center of Excellence for Innovation in Chemistry, \\ Faculty of Science, Khon Kaen University, Khon Kaen 40002, Thailand \\ *Corresponding author: E-mail: jitlada.v@msu.ac.th, jitlada_v@yahoo.com \\ Tel. +66 4375 4246; fax: +6643
}

Received: 06-03-2017

\begin{abstract}
An ionic liquid-assisted liquid-liquid microextraction based on the solidification of floating organic droplet (ILSFODLLME) was investigated for analysis of four herbicide residues (i.e. simazine, atrazine, propazine, and linuron) by high performance liquid chromatography. For ILSFOD-LLME, the optimal extraction conditions were $5 \%$ w/v Na $\mathrm{SO}_{4}, 30$ $\mu \mathrm{L}\left[\mathrm{C}_{4} \mathrm{MIM}\right]\left[\mathrm{PF}_{6}\right] \mathrm{RTIL}, 100 \mu \mathrm{L}$ of 1 -octanol, ultrasonication time $30 \mathrm{~s}$ and centrifugation at $5000 \mathrm{rpm}$ for $5 \mathrm{~min}$. Under the optimal conditions, linearity was obtained within the range of $0.1-1000 \mu \mathrm{g} \mathrm{kg}^{-1}$, with the correlation coefficients greater than 0.999. The high enrichment factors of the target analytes were in the range of 64.5-139.9 and low limit of detection could be obtained. A modified QuEChERS was applied for fruit sample preparation before analysis. Matrix effects were also investigated using matrix matched standards for construction of the calibration graph. The proposed method has been successfully applied for extraction and preconcentration of herbicide residues in fruit samples, and good recoveries in the range of $87.32 \%$ to $99.93 \%$ were obtained.
\end{abstract}

Keywords: QuEChERS; ILSFOD-LLME; ionic liquid; extraction; HPLC; herbicides

\section{Introduction}

Triazines and phenylureas are widely used in agriculture around the world as selective pre- and post-emergence herbicides for the control of broadleaf and grassy weeds. ${ }^{1}$ The intensive application of herbicides has resulted in the contamination of the atmosphere, ground and wastewaters, agricultural products and, consequently, in the direct and indirect pollution of food and food products. ${ }^{2}$ The European Union (EU) legislation harmonizes a maximum residue limits (MRLs) of the pesticides and fixes default value of MRLs at $0.01 \mathrm{mg} \mathrm{kg}^{-1}$ for human food and animal feeding stuffs. ${ }^{3}$ Because of these restrictions, it is important to develop simple, rapid, environmentally friendly and sensitive analytical methods for monitoring of trace level of trizine and phenylurea herbicides.

Almost all of the analytical methods for herbicide residues are based on separation techniques, i.e. gas chromatography (GC), high-performance liquid chromatography (HPLC), and capillary electrochromatography. High-performance liquid chromatography (HPLC) ${ }^{4,5}$ with 
UV and PDA detection has been adopted as an effective and reliable technique for the determination of selected herbicides. Due to the low concentration of these compounds and matrix complexity of real sample, an effective sample preparation and preconcentration can be used. Sample pretreatment is an important step in chemical step, especially in the analysis of trace analytes in environmental samples, ${ }^{6}$ and compensates for the drawbacks of UV detector. The quick, easy, cheap, effective, rugged and safe (QuEChERS) method has been presented for the analysis of pesticide residues in fruits and vegetables. ${ }^{7}$ It is based on the acetonitrile extraction, addition of salts to induce partition and then clean-up by dispersive solidphase extraction (DSPE) with sorbents, such as C18, primary secondary amine (PSA) and graphitized carbon black (GCB) ${ }^{8}$ It provides some advantages including high recovery for wide polarity and volatility range of pesticides and the use of small amounts of organic solvent. However, one of the main drawbacks of QuEChERS methodology is that there is no pesticide concentration step in the final extract. ${ }^{9}$

Dispersive liquid-liquid microextraction (DLLME) has been investigated to resolve this problem. However, one of the main drawbacks of DLLME methodology is that there is toxic organic solvent as extraction solvent such as chlorobenzene, chloroform and carbon tetrachloride. Therefore, the development of sample preparation methods based on green analytical chemistry is highly interesting to investigate. ${ }^{10}$ Ionic liquids (ILs) consist of organic cations and organic or inorganic anion with some special characteristics, such as negligible vapor pressure, good chemical and thermal stability, good ability to dissolve both organic and inorganic compounds, as well as adjustable miscibility and polarity. ${ }^{11,12}$ At least part of the current interest is due to the favorable environmental properties of ILs, which support their use as green solvents in sample preparation processes. ${ }^{13}$ In 2011, ILs have been used as extraction solvents in dispersive liquid-liquid microextraction (DLLME), ${ }^{14,15}$ microwave assisted ionicliquid microextraction (MAILME), ${ }^{16}$ ionic liquid-salt aqueous two-phase floatation (ILATPF), ${ }^{17}$ and single drop microextraction (SDME). ${ }^{18}$

The first application by ionic-liquid foaming-based solvent floatation was reported in 2012 by Li et al. ${ }^{19}$ for trace level determination of triazine and phenylurea herbicides in yoghurt. In this work a strong and active oxidizing agent such as perchloric acid was used. In this study, a simple extraction procedure using acetonitrile, namely modified QuEChERS, followed by preconcentration with ionic liquid-assisted liquid-liquid microextraction based on the solidification of floating organic droplet (ILSFODLLME) was investigated for determination of some herbicides, including simazine, atrazine, propazine, and linuron. The experimental parameters affecting the extraction efficiency and enrichment factor were investigated and the proposed method was applied to analyze surface water and fruit samples. The satisfactory recovery was achieved. Compared to DLLME method, the proposed method offers advantage of extraction and preconcentration in a simple and sensitive extraction step.

\section{Experimental}

\section{1. Chemicals and Reagents}

All reagents were of at least analytical reagent grade. All herbicide standards of herbicides including simazine, atrazine, propazine, and linuron were obtained from Fluka (Germany). The stock solutions of each herbicide were prepared at $1000 \mathrm{mg} \mathrm{L}^{-1}$ by dissolving each herbicide standard in methanol. Working standard solutions were prepared by diluting the stock solution with water. Methanol $(\mathrm{MeOH})$, acetonitrile $(\mathrm{ACN})$ and 1-octanol of HPLC grade were obtained from Merck (Germany). Sodium chloride $(\mathrm{NaCl})$ and anhydrous sodium sulphate $\left(\mathrm{Na}_{2} \mathrm{SO}_{4}\right)$ were obtained from Ajax Finechem (New Zealand), sodium acetate $\left(\mathrm{CH}_{3} \mathrm{COONa}\right)$ and sodium carbonate $\left(\mathrm{Na}_{2} \mathrm{CO}_{3}\right)$ were obtained from Carlo Erba (France). 1-butyl-3-methylimidazolium hexafluorophosphate $\left[\mathrm{C}_{4} \mathrm{MIM}\right]\left[\mathrm{PF}_{6}\right]$ RTIL was provided by Merck (Germany). Aqueous solutions were prepared with deionized water from RiOs ${ }^{\mathrm{TM}}$ Type I Simplicity 185 (Millipore Waters, USA) with the resistivity of $18.2 \mathrm{M} \Omega . \mathrm{cm}^{1}$.

\section{2. Instrumentation}

Chromatographic separation was performed on a Waters 1525 binary HPLC pump (USA), a Rheodyne injector with a sample loop of $20 \mu \mathrm{L}$ and a Waters 2489 UV/Visible detector. The Empower software was used for data acquisition. A LiChroCART RP-8 endcapped (4.6 $\times$ $150 \mathrm{~mm}, 5.0 \mu \mathrm{m}$ ) column (Merck, Germany) was used. A centrifuge (Centurion, England) was used for complete phase separation. An ultrasonic bath (Dksh, Germany) and a vortex mixer (Fisher Scientific, USA) were also used.

\section{3. Ionic Liquid-Assisted Liquid-Liquid Microextraction based on the Solidification of Floating Organic Droplet Procedure}

A volume of $10.00 \mathrm{~mL}$ of the standard solution (or sample solution) and $5 \% \mathrm{w} / \mathrm{v}$ of $\mathrm{Na}_{2} \mathrm{SO}_{4}$ was placed in a conical bottom tube. The solution was then vortexed before adding $30 \mu \mathrm{L}$ of $\left[\mathrm{C}_{4} \mathrm{MIM}\right]\left[\mathrm{PF}_{6}\right]$ RTIL. Then, $100 \mu \mathrm{L}$ of 1 -octanol was rapidly injected into the solution through the $1-\mathrm{mL}$ syringe and the tube was ultrasonicated for $30 \mathrm{~s}$ to obtain the mass transfer and provide high extraction efficiency. In order to complete the phase separation, the tube was centrifuged at $5000 \mathrm{rpm}$ for $5 \mathrm{~min}$ and the reconstituted solution was floated on the top of the solution. The 
upper phase ( 100 to $150 \mu \mathrm{L})$ was directly injected into HPLC. The concentrations of the reagents used in this work were optimized (see Optimization of ILSFODLLME).

\section{4. Chromatographic Separation Conditions}

After extraction procedure, four herbicides were separated using isocratic elution of 52\% $(\mathrm{v} / \mathrm{v})$ methanol in

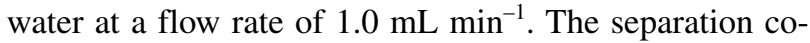
lumn was at room temperature. The detection was at 220 $\mathrm{nm}$. Four herbicides were separated within $7 \mathrm{~min}$ with the elution order of simazine, atrazine, propazine, and linuron. The retention time $\left(t_{R}\right)$ and resolution $(R s)$ are shown in Table 1.

Table 1. The retention time $\left(t_{R}\right)$ and resolution (Rs) of the studied compounds after HPLC analysis

\begin{tabular}{lcc}
\hline Analyte & Retention time $\left(\mathbf{t}_{\mathbf{R}}, \mathbf{m i n}\right)$ & Resolution $(\mathbf{R s})$ \\
\hline Simazine & 1.48 & - \\
Atrazine & 4.65 & 3.72 \\
Propazine & 6.20 & 4.44 \\
Linuron & 6.93 & 2.16 \\
\hline
\end{tabular}

\section{5. Sample Preparation}

Fruit samples including orange, guava, apple and grape were randomly purchased from local markets at Mahasarakham province in Northeast Thailand. The edible parts of fruit samples $(500 \mathrm{~g})$ were cut and blended using a commercial food mixer. A modified QuEChERS method ${ }^{20}$ was applied for sample preparation of the studied fruit samples. Briefly the procedure was as follows: $10 \mathrm{~g}$ of sample was placed in a $50-\mathrm{mL}$ centrifugation tube and mixed with $25 \mathrm{~mL}$ of $1 \%(\mathrm{v} / \mathrm{v})$ acetic acid in acetonitrile, and the mixture was vortexed for $1 \mathrm{~min}$. After that, sodium acetate and anhydrous magnesium sulphate $(15 \mathrm{~g})$ were added and the mixture was immediately shaken manually. The solution was then centrifuged at $3500 \mathrm{rpm}$ for $10 \mathrm{~min}$. The supernatant was subsequently evaporated to dryness using a rotary evaporator $\left(40{ }^{\circ} \mathrm{C}\right.$ water bath). The resulting residue was re-dissolved with $10.00 \mathrm{~mL}$ of water before extraction by ionic liquid-assisted liquid-liquid microextraction based on the solidification of floating organic droplet and analysis using HPLC.

Matrix-match calibration standards were prepared by adding known amounts of selected herbicides from $0.01-0.50 \mu \mathrm{g} \mathrm{g}^{-1}$ to the real sample extracts. In order to confirm the accuracy of the proposed method, recovery was tested. For recovery determinations, samples of blended fruit were spiked with the standard solution at three levels of concentration, 10,50 and $100 \mu \mathrm{g} \mathrm{kg}^{-1}$, for each of herbicide. The spiked samples were allowed to stand for
10 min before extraction to allow the spiked solution to penetrate the test materials.

\section{Results and Discussion}

\section{1. Optimization of Conditions for ILSFOD-LLME}

Several extraction parameters for ILSFOD-LLME such as salt addition, type and volume of RTIL, type and volume of extraction solvent, vortex, ultrasonication and centrifugation time, were investigated and the optimum conditions have been established. All the experiments were performed in triplicate by spiking $10 \mathrm{~mL}$ of water with $50 \mu \mathrm{g} \mathrm{kg}^{-1}$ of each herbicide and the mean of the results was used for optimization of the extraction efficiency of the method.

Generally, the addition of salt could increase the ionic strength of the aqueous medium with an electrolyte, reduce the solubility of both analytes and the RTIL in the aqueous sample solution and promote analyte transfer into the organic phase. ${ }^{21}$ To investigate the effect of salt addition on the extraction efficiency, various kinds of salts including $\mathrm{NaCl}, \mathrm{Na}_{2} \mathrm{SO}_{4}, \mathrm{Na}_{2} \mathrm{CO}_{3}, \mathrm{CH}_{3} \mathrm{COONa}$ were studied with the concentration of each salt being kept constant at $1 \%(w / v)$, and the results were compared with those obtained from the process without salt addition. As shown in Figure 1a, it was found that the addition of $\mathrm{Na}_{2} \mathrm{SO}_{4}$ provided higher extraction efficiency in terms of peak area of target herbicides. Therefore, $\mathrm{Na}_{2} \mathrm{SO}_{4}$ was selected for further study.

The effect of salt addition on the extraction efficiency in terms of peak area was investigated by the addition of different concentrations of $\mathrm{Na}_{2} \mathrm{SO}_{4}$ from 1 to $10 \%$ $(w / v)$ into aqueous sample solution while keeping other experimental parameters constant. As shown in Figure 1b, the results of this study indicated that peak areas of selected herbicides increased with the increase in $\mathrm{Na}_{2} \mathrm{SO}_{4}$ up to $5 \%(w / v)$. Beyond this point, the extraction efficiency decreased because higher amounts caused an increase of the solubility of the RTIL in aqueous phase at high ionic strength, therefore reducing the volume of the sediment (RTIL) phase. ${ }^{22}$ Consequently, $\mathrm{Na}_{2} \mathrm{SO}_{4} 5 \%(w / v)$ was used for further studies.

Selection of the appropriate RTIL, is an important parameter in order to obtain satisfactory extraction performance of the target analytes. RTIL could accelerate the emulsification of extraction solvent into the aqueous sample solution under ultrasound, resulting in increasing the extraction recovery. To work as an alternative solvent, an RTIL must meet certain requirements, such as being insoluble in water, having a low volatility and high extraction capability. ${ }^{22}$ Based on these consideration, 1-butyl-3methylimidazolium hexafluorophosphate $\left[\mathrm{C}_{4} \mathrm{MIM}\right]\left[\mathrm{PF}_{6}\right]$ RTIL was used in this study owing to its low viscosity and 
compatability to chromatographic system, compared with $\left[\mathrm{C}_{6} \mathrm{MIM}\right]\left[\mathrm{PF}_{6}\right]$ and $\left[\mathrm{C}_{8} \mathrm{MIM}\right]\left[\mathrm{PF}_{6}\right] .{ }^{23}$ The effect of the RTIL volume was studied in the range of $5-50 \mu \mathrm{L}$ (data not shown). It was found that symmetrical peaks, good baseline and high sensitivity was observed when $\left[\mathrm{C}_{4} \mathrm{MIM}\right]\left[\mathrm{PF}_{6}\right] 30 \mu \mathrm{L}$ was added. Thus, RTIL $30 \mu \mathrm{L}$ was choosen as disperser solvent.

The selection of suitable extraction solvent is of a great importance for the extraction of selected herbicides. The extraction solvent is dispersed as fine droplets in the sample solution, which is convenient for the mass transfer of the target analytes from the aqueous phase into the organic phase. 1-octanol (density, $0.8240 \mathrm{~g} \mathrm{~m}$ $\mathrm{L}^{-1}$ ), 1-dodecanol (density, $0.8309 \mathrm{~g} \mathrm{~mL}^{-1}$ ) and 2-dodecanol (density, $0.8290 \mathrm{~g} \mathrm{~mL}^{-1}$ ) were investigated as an extraction solvent (data not shown). It was observed that 1-octanol provided high extraction efficiency because 1-octanol has a lower density than the other extraction solvents and the solubility of 1-octanol in the common dispersive solvent was low. Therefore, 1-octanol was considered as an appropriate extraction solvent for the microextraction step.

The volume of the extraction solvent in microextraction step has a direct influence on the volume of the floated phase and substantial enrichment factor for the final concentration. ${ }^{26}$ Different volumes of 1-octanol (50, 100, $150,200,250$, and $300 \mu \mathrm{L}$ ) were investigated with the other experimental parameters being kept constant. It was found that if the extraction solvent volume is $50 \mu \mathrm{L}$, the solution cannot complete phase separation. Moreover, the extraction solvent volume more than $100 \mu \mathrm{L}$ decreased the peak areas of target herbicides, which may be due to the increased extract volume with the analyte signal decreased accordingly. As can be seen from Figure 1c, the highest extraction efficiency was obtained using $100 \mu \mathrm{L}$ of 1 octanol. Therefore, $100 \mu \mathrm{L}$ of 1 -octanol was selected for further studies.

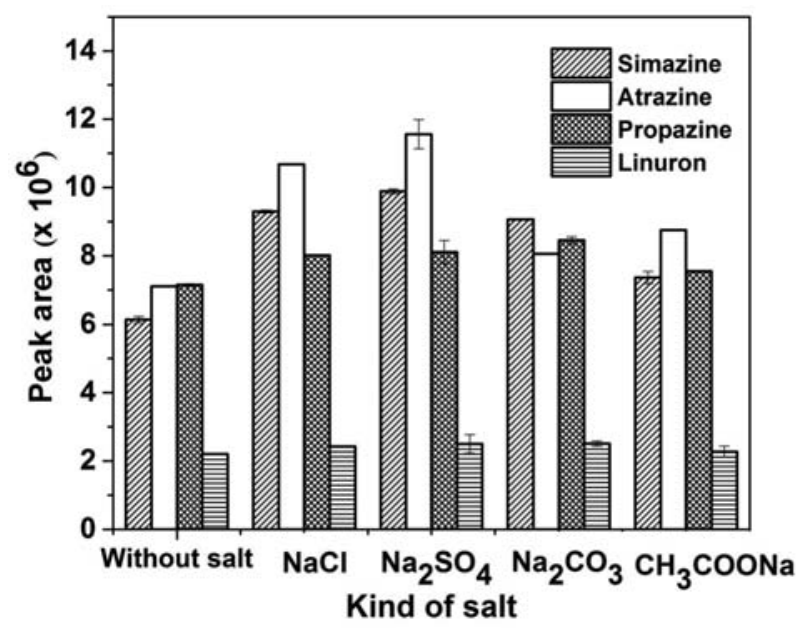

Figure 1a. Effect of salt addition on the extraction of selected herbicides

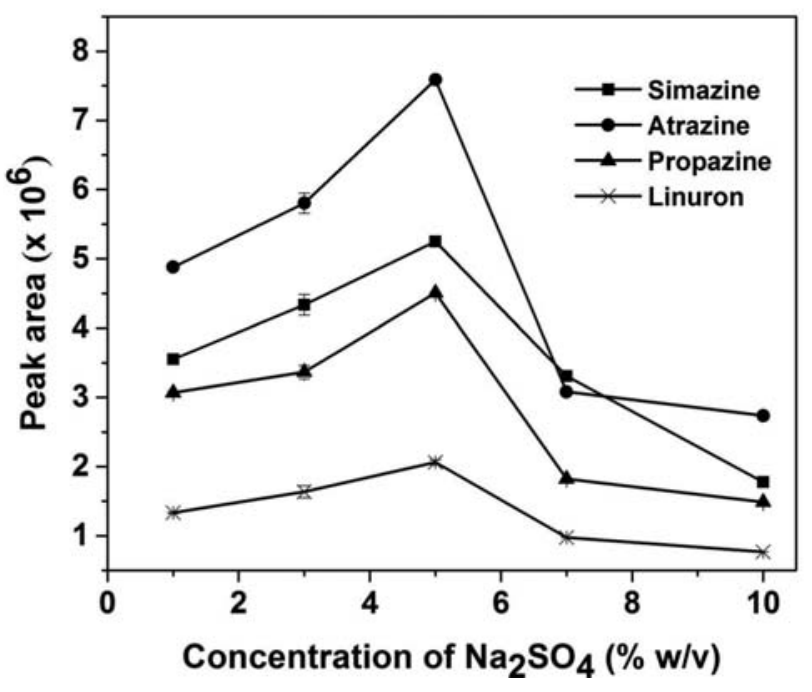

Figure 1b. Effect of concentration of salt on the extraction of selected herbicides

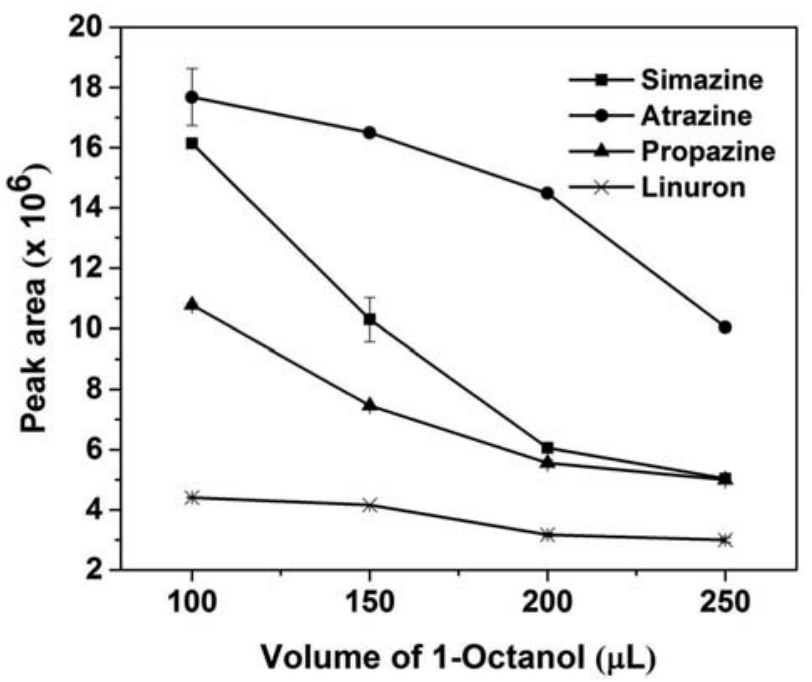

Figure 1c. Effect of volume of 1-octanol on the extraction of selected herbicides

Generally, the dispersion of the extraction solvent into the aqueous sample could depend on the rotational speed, vortex and ultrasonication time. ${ }^{25}$ Both rapid dispersion and mass transfer processes are the most important parameters in the extraction process, which is regarded as the interval time between the formation of cloudy solution and before centrifuging. The effect of the ultrasonication time affects the mass transfer between two phases in the extraction procedure, and the influence of ultrasonication time on the peak area was studied in the range of 30-150 s, under the optimal experimental conditions (data not shown). Results revealed that there was no significant effect on the extraction efficiencies at different extraction times. In the experiment, $30 \mathrm{~s}$ was chosen as extraction time. 
In extraction process, centrifugation time affects the size of the settled phase and the concentration of analyte in the extract phase. The effect of centrifugation time on the extraction efficiency of the proposed method was investigated by varying the centrifugation time from 2-10 min, at the speed of $3500 \mathrm{rpm}$ (data not shown). It was observed that the peak areas of the analyte slightly increased up to $5 \mathrm{~min}$, and then stayed constant. Thus, centrifugation time 5 min was selected for further experiments.

\section{2. Analytical Performances}

Quantitative parameters of the proposed method such as linear ranges, linear equation, coefficient of determination $\left(\mathrm{R}^{2}\right)$, precision, limit of detection (LOD), limit of quantitation (LOQ) and enrichment factor (EF) were evaluated under the optimal conditions (Table 2). Before extraction using the proposed method, the selected herbicides show linearity in the range from 10 to $5000 \mu \mathrm{g} \mathrm{kg}^{-1}$ with correlation coefficient $\left(\mathrm{R}^{2}\right)$ greater than 0.98 . Limits of detection (LODs) of the analytes were determined based on the signal to noise $(\mathrm{S} / \mathrm{N})$ ratio of 3 and found to be $10 \mu \mathrm{g} \mathrm{kg}^{-1}$ for all compounds. The limit of quantitation (LOQ) $(\mathrm{S} / \mathrm{N}=10)$ was found to be $30 \mu \mathrm{g} \mathrm{kg}^{-1}$. After extraction using the proposed method, the selected herbicides exhibit good linearity in the range from 0.1 to $1000 \mu \mathrm{g}$ $\mathrm{kg}^{-1}$ with correlation coefficient $\left(\mathrm{R}^{2}\right)$ of $0.9991-0.9997$. Limits of detection (LODs) of the analytes were determined based on the signal to noise $(\mathrm{S} / \mathrm{N})$ ratio of 3 and found in the range of $0.01-0.10 \mu \mathrm{g} \mathrm{kg}^{-1}$. The limit of quantitation $(\mathrm{LOQ})(\mathrm{S} / \mathrm{N}=10)$ was found in the range of $0.03-0.30 \mu \mathrm{g} \mathrm{kg}^{-1}$. In order to test the reproducibility of the proposed method, precision in terms of intra-day and inter-days were studied by replicate injection of the stan-

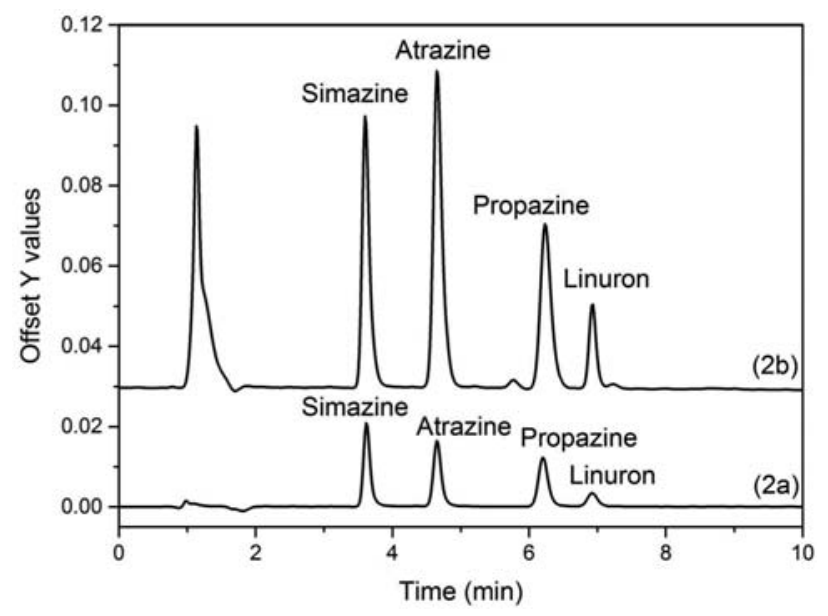

Figure 2. Chromatogram obtained for the separation of selected herbicides by (a) direct HPLC injection and (b) after preconcentration using ILSFOD-LLME combined with HPLC: concentration of all standard herbicides was $500 \mu \mathrm{g} \mathrm{kg}^{-1}$. dard mixture of $0.01 \mu \mathrm{g} \mathrm{kg}^{-1}$ each in a day $(n=5)$ and several days $(n=3 \times 5)$. The relative standard deviations (RSDs) were less than $2.88 \%$ and $6.38 \%$ for retention time $\left(t_{\mathrm{R}}\right)$ and peak area, respectively. The enrichment factor $(\mathrm{EF})$, defined as the concentration ratio of the analytes in the settled phase $\left(C_{s e t}\right)$ and in the aqueous sample $\left(C_{o}\right)$, were in the range of 64.5-139.9. The chromatograms obtained for the separation of selected herbicides by direct HPLC injection (Figure 2a) and ILSFOD-LLME combined with HPLC (Figure 2b) were compared. Using the proposed ILSFOD-LLME, the chromatographic signals of selected herbicides were increased.

\section{3. Application to Real Samples}

To test the applicability of the method for selected herbicides determination in fruit samples, four fruits were collected and examined. Matrix effects are known to be problematic in pesticide residue analysis, which can result in either decreased detection response or increased analytical signal. ${ }^{8}$ The extent of matrix effects can be calculated as the percent differences in slopes of the calibration graphs from matrix-matching vs. those from standards in solvent-only. ${ }^{26}$ In this work, matrix-matched calibration was used for quantitation of the selected herbicides in fruit samples. The working linear range was $0.1-50 \mu \mathrm{g} \mathrm{kg}^{-1}$. The slope of the matrix-matched calibration graph is dependent on the sample matrix, however, the correlation coefficients $\left(R^{2}\right)$ of greater than 0.999 were obtained for all compounds (as shown in Table 3). From the analytical results, all target herbicides frequently appeared in studied samples. The results are summarized in Table 4 . The concentration ranges of residues were $2.0-4.0 \mu \mathrm{g} \mathrm{kg}^{-1}$ for simazine, $3.0-7.0 \mu \mathrm{g} \mathrm{kg}^{-1}$ for atrazine, $0.5-4.0 \mu \mathrm{g} \mathrm{kg}^{-1}$ for propazine, and $0.2-4.0 \mu \mathrm{g}$

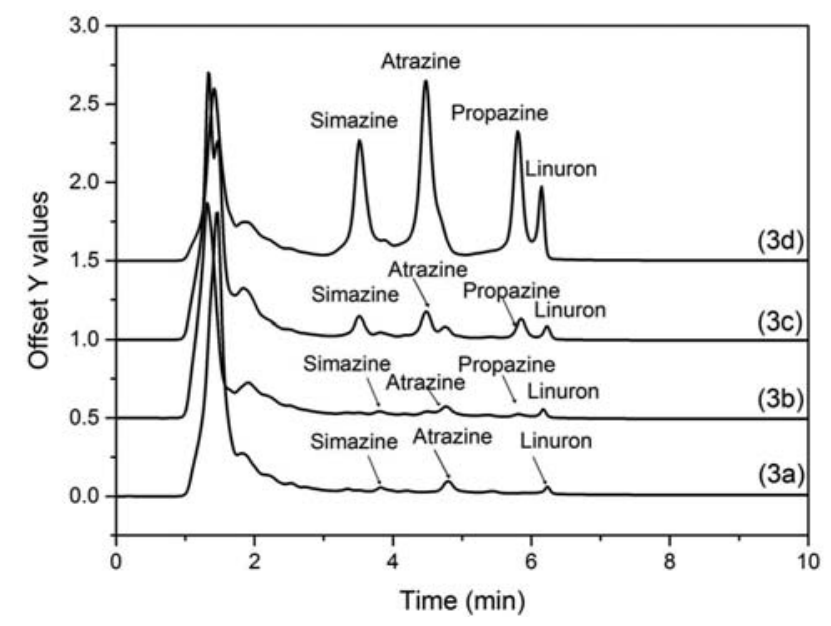

Figure 3. Chromatogram of (a) orange sample, (b) orange sample spiked at $10 \mu \mathrm{g} \mathrm{kg}^{-1}$ of each herbicide, (c) orange sample spiked at $50 \mu \mathrm{g} \mathrm{k}^{-1}$ of each herbicide, and (d) orange sample spiked at 100 $\mu \mathrm{g} \mathrm{\textrm {kg } ^ { - 1 }}$ of each herbicide 


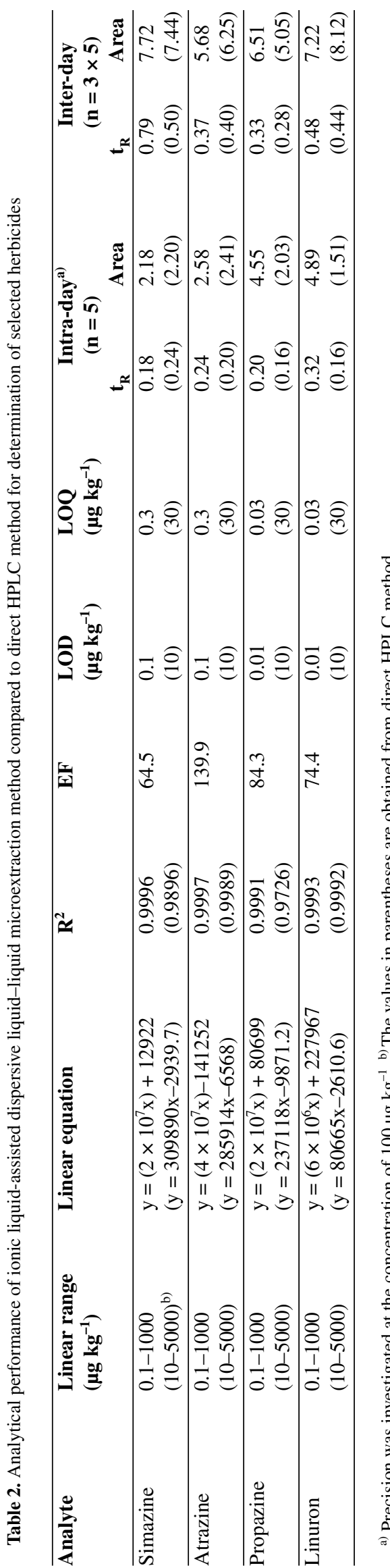

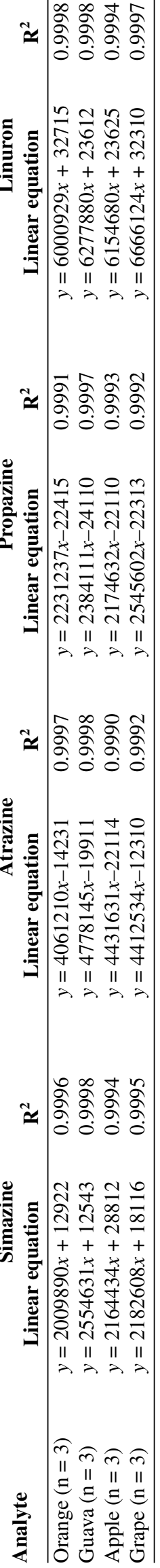

$\mathrm{kg}^{-1}$ for linuron. However, the amount of some herbicides found in fruit sample was lower than the MRLs established by EU (simazine, $0.01 \mathrm{mg} \mathrm{kg}^{-1}$ in orange, apple, and guava; atrazine and linuron, $0.05 \mathrm{mg} \mathrm{kg}^{-1}$ in orange, apple, grape, and guava).

In order to validate the accuracy of the presented extraction method, different amounts of target analytes were spiked to fruit samples at concentration levels of 10,50 , and $100 \mu \mathrm{g} \mathrm{kg}^{-1}$. The spiked samples were analyzed and the results are shown in Table 5. Recoveries were between $87.32 \%$ and $99.93 \%$, and RSD values ranged from $1.15 \%$ to $6.57 \%$. The results demonstrated that the matrix effects caused by the fruit samples had a negligible affect on the efficiency and sensitivity of the proposed method. Figure 3 shows chromatograms corresponding to real sample and real sample spiked with selected herbicides.

\section{Conclusions}

A method of ILSFOD-LLME coupled to HPLC has been investigated for sensitive and robust determination of selected herbicides in fruit samples. The effective sample preparation using modified QuEChERS method was used. The target compounds were simply extracted by 1-octanol with ionic liquid $\left[\mathrm{C}_{4} \mathrm{MIM}\right]\left[\mathrm{PF}_{6}\right]$ as green disperser solvent, which is less toxic than the solvent normally used in the typical conventional DLLME. The matrix-matched calibration provided good recoveries in real sample determination at trace levels of herbicides. The proposed method shows good analytical features providing low limit of detection at the levels of $0.1 \mu \mathrm{g} \mathrm{kg}^{-1}$ which are below the acceptable MRLs established by EU. A high preconcentration factor in the range of 64.5 to 139.9 , good recoveries and high reproducibility were also obtained. The proposed method offers the advantages of simplicity and sensitivity.

\section{Acknowledgements}

The authors gratefully acknowledge financial supports for this research from Center of Excellence for Innovation in Chemistry (PERCH-CIC), Mahasarakham University, National Research Council of Thailand (NRCT), The Thailand Research Fund (TRF) and the Commission on Higher Education (CHE). 
Table 4. Analysis of selected herbicides in fruit juice samples

\begin{tabular}{lcccc}
\hline \multirow{2}{*}{ Samples } & Simazine & \multicolumn{2}{c}{ Amount found $\pm \mathbf{S D}, \boldsymbol{\mu g} \mathbf{~ k g}^{-\mathbf{1}}(\mathbf{n}=\mathbf{3})$} \\
& Atrazine & Propazine & Linuron \\
\hline Orange $(\mathrm{n}=3)$ & $4.0 \pm 0.02$ & $7.0 \pm 0.10$ & - & $0.2 \pm 0.01$ \\
Guava $(\mathrm{n}=3)$ & - & $3.0 \pm 0.20$ & $0.5 \pm 0.01$ & $4.0 \pm 0.01$ \\
Apple $(\mathrm{n}=3)$ & - & $4.0 \pm 0.01$ & $4.0 \pm 0.01$ & - \\
Grape $(\mathrm{n}=3)$ & $2.0 \pm 0.10$ & - & - & - \\
\hline
\end{tabular}

$-;$ not detected

Table 5. Recovery obtained from the determination of target herbicides in fruit juice samples $(n=3)$

\begin{tabular}{|c|c|c|c|c|c|c|c|c|c|}
\hline \multirow[t]{2}{*}{ Analytes } & \multirow{2}{*}{$\begin{array}{l}\text { Spiked } \\
\left(\mu \mathrm{gg}^{-1}\right)\end{array}$} & \multicolumn{2}{|c|}{ Orange $(n=3)$} & \multicolumn{2}{|c|}{ Guava $(n=3)$} & \multicolumn{2}{|c|}{ Apple $(n=3)$} & \multicolumn{2}{|c|}{ Grape $(n=3)$} \\
\hline & & $\operatorname{RR}(\%)$ & RSD (\%) & $\operatorname{RR}(\%)$ & $\operatorname{RSD}(\%)$ & $\operatorname{RR}(\%)$ & RSD $(\%)$ & $\operatorname{RR}(\%)$ & $\operatorname{RSD}(\%)$ \\
\hline \multirow[t]{3}{*}{ Simazine } & 10 & 93.55 & 1.80 & 97.27 & 1.23 & 97.78 & 4.63 & 98.65 & 1.56 \\
\hline & 50 & 97.13 & 2.30 & 95.83 & 2.64 & 92.37 & 1.54 & 91.72 & 1.78 \\
\hline & 100 & 94.63 & 1.02 & 96.56 & 2.59 & 95.33 & 2.65 & 96.57 & 1.58 \\
\hline \multirow[t]{3}{*}{ Atrazine } & 10 & 92.63 & 2.32 & 87.32 & 2.33 & 95.87 & 2.73 & 87.75 & 2.27 \\
\hline & 50 & 93.23 & 3.05 & 93.62 & 2.61 & 97.39 & 3.54 & 90.23 & 3.23 \\
\hline & 100 & 97.69 & 3.04 & 92.18 & 2.27 & 93.43 & 1.41 & 92.17 & 3.57 \\
\hline \multirow[t]{3}{*}{ Propazine } & 10 & 92.87 & 1.15 & 92.17 & 2.83 & 89.82 & 4.54 & 92.83 & 2.76 \\
\hline & 50 & 93.53 & 2.22 & 98.78 & 3.37 & 99.58 & 3.58 & 91.57 & 6.57 \\
\hline & 100 & 92.12 & 2.35 & 92.23 & 2.63 & 91.27 & 4.53 & 89.84 & 5.38 \\
\hline \multirow[t]{3}{*}{ Linuron } & 10 & 99.78 & 3.43 & 99.67 & 2.78 & 98.67 & 4.73 & 99.93 & 2.23 \\
\hline & 50 & 91.63 & 2.33 & 91.23 & 1.15 & 92.25 & 4.23 & 92.25 & 2.37 \\
\hline & 100 & 94.32 & 2.78 & 90.43 & 3.75 & 93.57 & 4.41 & 91.58 & 2.48 \\
\hline
\end{tabular}

RR: Relative recovery RSD: Relative standard deviation

\section{References}

1. R. Fang, G. Chen, L. Yi, Y. Shao, L. Zhang, Q. Cai, J. Xiao, Food Chem. 2014, 145, 41-48. https://doi.org/10.1016/j.foodchem.2013.08.028

2. X. Yang, R. Yu, S. Zhang, B. Cao, Z. Liu, L. Lei, N. Li, Z. Wang, L. Zhang, H. Zhang, Y. Chen, J. Chromatogr. B 2014, 972, 111-116.

https://doi.org/10.1016/j.jchromb.2014.10.001

3. Pesticide EUMRLs Database 2008

4. H. R. Sobhi, Y. Yamini, R. H. Hosseini, B. Abadi, J. Pharmaceut. Biomed. 2007, 45, 769-774. https://doi.org/10.1016/j.jpba.2007.09.026

5. E. Bichon, M. Dupuis, B. L. Bizec, F. André, J. Chromatogr. B 2006, 838, 96- 106. https://doi.org/10.1016/j.jchromb.2006.04.019

6. G. Zhao, S. Song, C. Wang, Q. Wu, Z. Wang, Anal. Chim. Acta 2011, 708, 155-159.

https://doi.org/10.1016/j.aca.2011.10.006

7. J. Vichapong, R. Burakham, S. Srijaranai, K. Grudpan, Talanta 2011, 84, 1253-1258.

https://doi.org/10.1016/j.talanta.2011.01.002

8. N. Wongsa, R. Burakham, Food Anal. Methods 2012, 5, 849-855. https://doi.org/10.1007/s12161-011-9317-y

9. Y. Santaladchaiyakit, S. Srijaranai, J. Sep. Sci. 2014, 37, 3354-3361. https://doi.org/10.1002/jssc.201400699
10. M. Yang, P. Zhang, L. Hu, R. Lu, W. Zhou, S. Zhang, H. Gao, J. Chromatogr. A 2014, 1360, 47-56. https://doi.org/10.1016/j.chroma.2014.07.076

11. A. Martín-Calero, V. Pino, J. H. Ayala, V. González, A. M. Afonso, Talanta 2009, 79, 590-597. https://doi.org/10.1016/j.talanta.2009.04.032

12. C. F. Poole, N. Lenca, Trends Anal. Chem. 2015, 71, 144 156. https://doi.org/10.1016/j.trac.2014.08.018

13. Y. Wang, J. You, R. Ren, Y. Xiao, S. Gao, H. Zhang, A. Yu, J. Chromatogr. A 2010, 1217, 4241-4246. https://doi.org/10.1016/j.chroma.2010.03.031

14. T. D. Nguyen, J. E. Yu, D. M. Lee, G.-H. Lee, Food Chem. 2008, 110, 207-213. https://doi.org/10.1016/j.foodchem.2008.01.036

15. M. Asensio-Ramos, J. Hernández-Borges, T. M. Borges-Miquel, M. Á. Rodríguez-Delgado, J. Chromatogr. A 2011 , 1218, 4808-4816. https://doi.org/10.1016/j.chroma.2010.11.030

16. S. Gao, J. You, X. Zheng, Y. Wang, R. Ren, R. Zhang, Y. Bai, H. Zhang, Talanta 2010, 82, 1371-1377. https://doi.org/10.1016/j.talanta.2010.07.002

17. J. Han, Y. Wang, C. Yu, C. Li, Y. Yan, Y. Liu, L. Wang, Anal. Chim. Acta 2011, 685, 138-145. https://doi.org/10.1016/j.aca.2010.11.033

18. X. Wen, Q. Deng, J. Guo, Spectrochim. Acta A 2011, 79, 1941-1945. https://doi.org/10.1016/j.saa.2011.05.095 
19. N. Li, R. Zhang, L. Nian, R. Ren, Y. Wang, H. Zhang, A. Yu, J. Chromatogr. A 2012, 1222, 22-28. https://doi.org/10.1016/j.chroma.2011.12.019

20. R. Romero-González, A. Garrido Frenich, J.L. Martínez Vidal, Talanta 2008, 76, 211-225. https://doi.org/10.1016/j.talanta.2008.02.041

21. J. Xue, X. Chen, W. Jiang, F. Liu, H. Li, J. Chromatogr. B 2015, 975, 9-17. https://doi.org/10.1016/j.jchromb.2014.10.029

22. M. Yang, X. Xi, X. Wu, R. Lu, S. Zhang, H. Gao, J. Chromatogr. A 2015, 1381, 37-47. https://doi.org/10.1016/j.chroma.2015.01.016
23. C. F. Poole, S. K. Poole, J. Chromatogr. A 2010, 1217, 2268-2286. https://doi.org/10.1016/j.chroma.2009.09.011

24. X. Xu, R. Su, X. Zhao, Z. Liu, Y. Zhang, D. Li, X. Li, H. Zhang, Z. Wang, Anal. Chim. Acta 2011, 707, 92-99. https://doi.org/10.1016/j.aca.2011.09.018

25. Z.-H. Yang, Y.-L. Lu, Y. Liu, T. Wu, Z.-Q. Zhou, D.-H. Liu, J. Chromatogr. A 2011, 1218, 7071-7077. https://doi.org/10.1016/j.chroma.2011.08.029

26. S. J. Lehotay, K. A. Son, H. Kwon, U. Koesukwiwat, W. Fu, K. Mastovska, E. Hoh, N. Leepipatpiboon, J. Chromatogr. A 2010, 1217, 2548-2560.

https://doi.org/10.1016/j.chroma.2010.01.044

\section{Povzetek}

Preučevali smo mikroekstrakcijo z ionsko tekočino, osnovano na strjeni plavajoči organski kapljici (ILSFOD-LLME) za analizo štirih preostankov herbicidov (simazin, atrazin, propazin in linuron) z visoko zmogljivo tekočinsko kromatografijo. Za ILSFOD-LLME so bili optimalni ekstrakcijski pogoji $5 \% \mathrm{w} / \mathrm{v} \mathrm{Na} \mathrm{SO}_{4}, 30 \mu \mathrm{L}\left[\mathrm{C}_{4} \mathrm{MIM}\right]\left[\mathrm{PF}_{6}\right] \mathrm{RTIL}, 100 \mu \mathrm{L}$ 1-oktanola, čas ultrazvoka $5 \mathrm{~min}$ in centrifugiranje pri $5000 \mathrm{rpm} 30 \mathrm{~s}$. Pri optimalnih pogojih je bila linearnost v območju $0,1-1000 \mu \mathrm{g} \mathrm{kg}^{-1}$, korelacijski koeficienti pa večji kot 0,999 . Visoki obogatitveni faktorji za analite so bili v območju 64,5-139,9, dobili smo tudi nizko mejo zaznave. Za pripravo vzorcev sadja pred analizo smo uporabili modificirano QuEChERS metodo. Raziskali smo tudi matrične učinke, tako da smo standarde v ustrezni matrici uporabili za pripravo umeritvene krivulje. Predlagano metodo smo uspešno uporabili za ekstrakcijo in predkoncentracijo ostankov herbicidov v vzorcih sadja, Dobili smo dobre izkoristke v območju 87,32\% do 99,93\%. 